\title{
Atendimento aos surdos nos serviços de saúde: acessibilidade e obstáculos
}

\author{
Care to the deaf patients in the Health services: \\ accessibility and obstacles
}

Recebido em: $14 / 06 / 2016$

Aceito em: $16 / 09 / 2016$
Dayane Bevilaqua NEVES; Ilana Mirian Almeida FELIPE;

Serlyjane Penha Hermano NUNES

Universidade Federal do Maranhão (UFMA). Av. dos Portugueses, 1966, Bacanga, São Luís, MA. CEP 65080-805, Brasil.

E-mail: serlyphn@yahoo.com.br

\section{ABSTRACT}

This is a descriptive qualitative study aiming to understand the deaf people accessibility to health services, diagnosing problems and obstacles. Nine deaf patients were interviewed using the Brazilian Sign Language - LIBRAS, with the aid of an interpreter. The data were evaluated using the Content Analysis (Theme mode) technique, which five categories: communication, feelings, perceptions, accessibility and $f$ autonomy. The data analysis revealed that there are a small number of health care professionals able to communicate using LIBRAS, and this fact complicates the communication between the patient and health workers. Moreover, deaf patients claim they rarely can find interpreters to assist them. Because the problems in establishing efficient communication, several Health services and information are inaccessible to deaf patients. Besides, the society still sees the deaf people as unable to make their own decisions regarding their health and therapy, keeping them dependent on others.

Keywords: deafness, accessibility, Health Care

\section{RESUMO}

Estudo descritivo com abordagem qualitativa com o objetivo de compreender a acessibilidade aos serviços de saúde entre pessoas surdas, diagnosticando problemas e obstáculos que enfrentam. Participaram nove adultos surdos, que foram entrevistados utilizando a Língua Brasileira de Sinais - LIBRAS, com auxílio de um intérprete. As análises foram realizadas com base na técnica de análise de conteúdo, modalidade temática, da qual emergiram cinco categorias: comunicação, sentimentos, percepção do surdo sobre o atendimento em saúde, acessibilidade aos serviços e falta de autonomia. A análise dos dados revelou que há um número reduzido de profissionais aptos a se comunicar usando a LIBRAS, o que dificulta a comunicação com o profissional de saúde que o atende, agravado pelo fato de que raramente encontram intérpretes para auxiliá-los. Muitos serviços e informações de saúde encontram-se inacessíveis aos surdos dada a deficiência em se estabelecer um processo de comunicação eficiente com o profissional de saúde, acrescido do fato de que a própria sociedade ainda vê o surdo como alguém incapaz de tomar suas próprias decisões em relação à sua saúde e terapia, mantendo-lhes na dependência de outras pessoas.

Palavras chave: Acesso aos serviços de saúde; Surdez; Saúde da pessoa com deficiência.

Palavras-chave: surdez, acessibilidade, Serviços de Saúde 


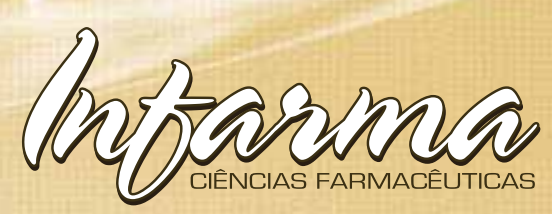

\section{INTRODUÇÃO}

Alguns indivíduos são considerados portadores de deficiência, por possuir uma limitação ou incapacidade ao desempenhar certas atividades. Segundo o Decreto $\mathrm{n}^{\circ}$ 5.296 de 2 de dezembro de 2004, estes podem ser deficientes físicos, auditivos, visuais ou mentais (1).

A deficiência auditiva pode ser congênita e adquirida e é definida como a diminuição da capacidade de percepção normal dos sons, de modo que a audição não tem sua funcionalidade total na vida comum. É diagnosticado como surdo o indivíduo com perda auditiva bilateral, parcial ou total, de 41 decibéis $(\mathrm{dB})$ ou mais, aferida por audiograma nas frequências de $500 \mathrm{HZ}, 1.000 \mathrm{HZ}$, $2.000 \mathrm{~Hz}$ e $3.000 \mathrm{~Hz}(1)$.

Segundo as informações adquiridas no censo de 2010 pelo Instituto Brasileiro de Geografia e Estatística (IBGE), a deficiência auditiva acomete aproximadamente 9,7 milhões de brasileiros, o que equivale a $5,1 \%$ da população total do país (2).

A pessoa surda compreende e interage com o mundo por meio de experiências visuais, manifestando sua cultura principalmente pelo uso da Língua Brasileira de Sinais (LIBRAS).

Portanto, diante dessa realidade, para que esses usuários pudessem ser assistidos adequadamente em sua saúde, seu atendimento, foi regulamentado o Decreto $\mathrm{n}^{\mathrm{o}}$ 5.626 de 22 de dezembro de 2005 (3), segundo o qual foi estabelecido que tanto no Sistema Único de Saúde (SUS), como nas empresas que detém concessão ou permissão de serviços públicos de assistência à saúde, deve haver profissionais capacitados para o uso de LIBRAS para tradução e/ou interpretação. Os surdos, mesmo sendo minoria, devem usufruir de maneira plena os serviços de saúde, bem como ter acesso a informações sobre medicamentos.

Como qualquer outro grupo populacional, as pessoas com deficiência auditiva precisam de acesso à saúde, não somente relacionado com a deficiência em si, mas também precisam ser assistidas por meio de medidas de prevenção, tanto as que são feitas em nível populacional, na forma de políticas ou campanhas de divulgação na mídia, como em nível individual, nas consultas com profissionais da saúde (4).

Diante das dificuldades que o usuário surdo enfrenta, um dos grandes obstáculos imposto a eles é o de usufruir de serviços de saúde com recursos eficientes para atendê-los, respeitando suas deficiências (5). Isso os leva a depender de outras pessoas para ter acesso aos serviços de saúde, comprometendo até mesmo sua cidadania, o que torna esses pacientes sujeitos passivos em seu próprio processo de assistência à saúde $(6,7)$.

Os profissionais de saúde deveriam compreender as necessidades das pessoas surdas, evitando má compreensão por parte dos usuários sobre como cuidar de si próprios, e como usar a medicação, o que pode colocar em risco sua segurança. Os serviços de saúde devem ser planejados considerando todos os possíveis pacientes que o utilizarão e isto inclui pacientes com deficiências diversas, como o paciente surdo. Melhorar a comunicação para lidar com pacientes surdos poderá resultar em melhor comunicação com todos os pacientes (8).

O acesso, pela população, aos serviços de saúde é fundamental para garantir a assistência à saúde eficiente e satisfatória. Os termos acesso e acessibilidade em saúde são complementares, pois a acessibilidade possibilita as pessoas chegarem aos serviços e o acesso permite o uso oportuno desses mesmos serviços para alcançar os melhores resultados possíveis (9). Assim, há, entre as necessidades de saúde e sua satisfação, a questão da acessibilidade. Essa, se não for plenamente garantida, poderá gerar obstáculos ao deficiente, inviabilizando o acesso aos serviços de saúde (10).

Estudos acerca dos problemas de acesso à saúde por pessoas com deficiência auditiva podem se constituir como um importante subsídio para o planejamento de ações voltadas para o treinamento e capacitação de recursos humanos no atendimento de pessoas com esse tipo de deficiência, bem como adaptar os métodos já utilizados na transmissão de informações a esse grupo especial. Dessa forma, os direitos de uso e acesso integral aos serviços de saúde, instituídos pela Constituição Federal e pelo SUS, poderiam lhes ser garantidos.

Dessa forma, esse trabalho teve o objetivo de compreender o acesso aos serviços de saúde entre pessoas surdas, bem como os problemas e obstáculos para o atendimento das mesmas.

\section{MÉTODOS}

Este estudo caracteriza-se como descritivo, com abordagem qualitativa. Esse tipo de análise foi usado para adentrar na percepção subjetiva dos surdos sobre a acessibilidade aos serviços para sua saúde, assim tornando o estudo mais próximo da realidade.

As coletas foram realizadas em uma escola de referência na educação de surdos em São Luís, MA, entre os meses de setembro a novembro de 2014. 
A pesquisa foi submetida ao Comitê de Ética em Pesquisa da Universidade Federal do Maranhão e foi aprovada sob o parecer $n^{\circ} 509.115 / 2014$. Os entrevistados foram informados acerca da pesquisa com o auxílio de um intérprete de LIBRAS e, uma vez concordando em participar, assinaram o Termo de Consentimento Livre e Esclarecido. Para garantir o anonimato, os sujeitos da pesquisa foram identificados no texto pela letra $\mathrm{S}$, seguidos de um número, de acordo com a ordem crescente das entrevistas realizadas.

$\mathrm{Na}$ escola estudam 22 alunos surdos. A pesquisa foi realizada no período noturno, devido aos alunos maiores de 18 anos estarem matriculados neste horário. Dos 14 alunos do turno analisado, somente 9 se encaixaram nos seguintes critérios: ser deficiente auditivo, com idade igual ou superior a 18 anos e fluência na comunicação por LIBRAS. Foram excluídos aqueles que tinham o diagnóstico prévio de deficiência intelectual e os que apresentaram dificuldades em compreender as perguntas, característica observadas no momento da entrevista pelo próprio pesquisador.

As informações foram obtidas por meio da aplicação de um questionário semi-estruturado com questões abordando assuntos referentes ao acesso da pessoa surda aos serviços de saúde e, nesse contexto, foram incluídos depoimentos acerca da comunicação entre o surdo e os profissionais, da compreensão de tais informações e das dificuldades vivenciadas por pessoas com tal deficiência.

As coletas de dados foram realizadas com o auxílio de um intérprete de LIBRAS, gravadas e transcritas para a análise dos discursos. Por meio da leitura flutuante do material coletado pôde-se identificar a totalidade do trabalho possibilitando a organização das informações do mesmo.

Os dados foram analisados com base na técnica de análise de conteúdo, modalidade temática. As unidades de registro foram definidas e recortadas, possibilitando que os dados fossem classificados e agregados conforme categorias comuns dentro do tema abordado, em seguida foram interpretados e discutidos embasados na literatura, sendo agrupados em quatro núcleos de sentido: 1) comunicação, 2) sentimentos: percepção do surdo sobre o atendimento em saúde, 3) compreensão da terapia e 4) falta de autonomia

\section{RESULTADOS E DISCUSSÃO}

Do total de sujeitos examinados, sete eram do gênero masculino e dois do gênero feminino, com idade entre 19 e 44 anos. Sete deles eram solteiros e cinco não souberam informar a renda familiar. Todos cursavam o Ensino Médio e quatro afirmavam ter vínculo empregatício. Somente um declarou ser oralizado, embora apenas três não tenham se comunicado dessa forma em momento algum durante a pesquisa.

Dois dos entrevistados relataram que sua deficiência auditiva foi adquirida quando crianças, um deles informando sarampo como agente causal. Os outros sete relataram surdez congênita. Nenhum deles utilizava aparelho auditivo embora quatro deles o possuíssem. Eles relataram desconforto, dores e muitos ruídos ao utilizá-lo, o que os fazia preferir a utilização de LIBRAS como forma de comunicação.

Os discursos foram transcritos, conforme a interpretação do tradutor de LIBRAS. e a partir deles as discussões teóricas sobre o assunto foram fundamentadas. Os resultados das entrevistas e sua discussão foram agrupados nos quatro núcleos de sentido referidos anteriormente.

Comunicação. Apenas três dos entrevistados relataram episódio único de atendimento por profissional da saúde que utilizava LIBRAS. Os outros, além de nunca terem presenciado esse fato, não esperavam atendimento qualificado ao procurar os serviços de saúde.

A linguagem é um instrumento poderoso de comunicação e não se pode negar aos surdos o direito de usufruir os benefícios de uma língua. Assim, aceitar as divergências do surdo e ter uma vivência diante das diversidades humanas é desafiador para a sociedade atual. Essa inclusão refere-se também ao atendimento adequado na área da saúde para os surdos, correspondendo as suas necessidades (11).

Para que haja inclusão, não é o surdo que tem que se adaptar às condições existentes, mas a sociedade que deve se preparar para atendê-los, tirando-os do isolamento e favorecendo uma melhor qualidade de vida (11). O profissional precisa despertar para essa necessidade e ser um instrumento facilitador de comunicação e auxílio aos surdos, e não um obstáculo a mais que eles precisam transpor para ter um atendimento adequado.

O artigo 196 da Constituição Brasileira regulamenta o direito à saúde, garantido pelo Estado (12). Todavia, para que esse direito seja plenamente estabelecido, os profissionais, como cidadãos, devem contribuir para que o exercício da saúde seja efetivado na comunidade surda. Uma das formas dos profissionais da saúde exercerem essa cidadania é compreendendo a realidade do surdo, sua dificuldade de expressão e ampliando sua 


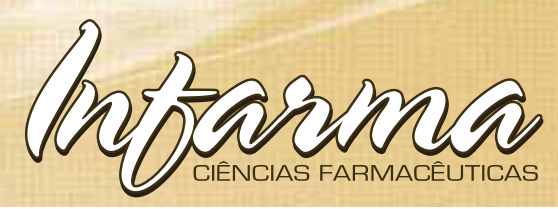

capacidade de comunicação através do uso da LIBRAS. A oportunidade de ampliar a comunicação do profissional poderia ser estimulada com ofertas de cursos de LIBRAS, por meio de uma iniciativa da direção dos estabelecimentos de saúde. Ou mesmo, o agendamento prévio com o interprete, para que no momento da consulta, o paciente surdo tenha mais acessibilidade a informações sobre sua saúde.

Quando o relacionamento entre o paciente e o profissional é marcado por um bloqueio de comunicação, produz-se um grande obstáculo para a promoção da saúde. O paciente surdo não consegue expressar seus problemas de forma compreensível e o profissional fica impossibilitado de demonstrar seus conhecimentos, inviabilizando o atendimento eficaz.

Outro estudo realizado com surdos também observou comprometimento no relacionamento entre eles e o profissional. Devido à falta de interação, não se pode criar um elo entre eles, o que confere dificuldade para ambos porque, na maioria das vezes, não há preparo do profissional para lidar com esse tipo de situação (11).

Um entrevistado conta sua experiência ao se comunicar com uma enfermeira, e compara com os outros atendimentos que já vivenciou.

\section{Eu gostei muito (quando encontrei um profissional} que se comunicou comigo). Agora, com outros, eu senti muita dificuldade de comunicação (S9).

Devido às dificuldades que enfrentam para relacionar-se, os surdos parecem sentir-se acolhidos quando encontram um profissional que saiba comunicar-se com eles, diferentemente do que acontece quando não conseguem se expressar no estabelecimento de saúde.

Uma pesquisa realizada com profissionais do Hospital Universitário do Rio de Janeiro constatou grandes falhas na compreensão que estes têm sobre a realidade dos pacientes surdos, e nas formas de lidar com eles. Apresentaram desde desconhecimento total, quanto ideias equivocadas sobre como se comunicar corretamente com os surdos, respeitando sua deficiência (13).

Uma vez que é notória a dificuldade que têm os profissionais de saúde em se comunicar com o paciente surdo, esses são acompanhados por familiares que são intermediários na comunicação. Mas, em muitos casos, os próprios acompanhantes não se comunicam por LIBRAS, limitando ainda mais a expressão dos surdos, ao descrever os seus sintomas e pedir ajuda.
Minha mãe não sabe LIBRAS, assim eu não tenho como falar pra ela. Ela me leva ao hospital, mas como não há comunicação com o médico, eu sinto muita dificuldade (S9).

Em relação à presença de intérpretes, que é garantida pelo Decreto ${ }^{0} 5.626$ (3), todos os entrevistados relataram que nunca os encontraram nos estabelecimentos de Saúde. O atendimento somente se dá na presença de um intérprete quando o próprio surdo tem a iniciativa de levá-lo, acompanhando-o.

Mesmo a presença de intérpretes não garante a inclusão efetiva, pois o atendimento se dá de forma mais eficaz por meio do relacionamento direto entre o profissional e o paciente. Na ausência de um intérprete, há dificuldade na comunicação do paciente surdo com o profissional e, embora a contratação de intérpretes traga auxílio, acaba resolvendo o problema de forma pontual e distorcendo a verdadeira perspectiva da inclusão (14).

Ainda sobre o Decreto $\mathrm{n}^{\mathrm{o}} 5.626$ (3), que garante a presença de intérpretes nos estabelecimentos de Saúde, cinco entrevistados não a conheciam. E mesmo os que estavam cientes dos seus direitos não entendiam porque o atendimento ao surdo estava sendo negligenciado. Gostariam que seus direitos fossem de fato garantidos e eles pudessem ter acesso ao profissional.

Com tantas dificuldades e limitações no processo de comunicação, eles acabam utilizando outras formas de linguagem não verbal para se expressar, como mímica ou leitura labial, o que impossibilita o relato fidedigno dos problemas de saúde dos surdos, sua história clínica e a descrição dos seus sintomas (15).

Como eles não apresentam deficiência visual, a escrita seria uma alternativa viável para a comunicação, mas a forma que os surdos escrevem é diferenciada gramaticalmente. O português é sua segunda língua, e eles apresentam dificuldades de se expressar e se fazer entender dessa forma. Acabam sendo uma espécie de estrangeiros inseridos no seu próprio país $(11,4)$.

Eu escrevo, mas até escrever é difícil, por que escrevemos diferente, ai ele não entende da mesma forma (S8).

Como há um entrave entre a informação disponível pelo profissional e a compreensão do paciente surdo, percebe-se uma falha na comunicação entre eles. Um resultado parecido foi encontrado em outra pesquisa onde também foi identificada a comunicação deficiente como 
principal parte no distanciamento entre o profissional de saúde e o surdo (7).

Autonomia. A dependência de familiares é relatada pelo grupo. Quatro deles foram auxiliados por suas mães, três por irmãos e um deles pelo pai. Houve também o acompanhamento por amigos por um dos entrevistados. Essa dependência de outros aconteceu tanto no transporte para o estabelecimento de saúde, quando para comunicação e a compreensão do tratamento.

Vou com minha mãe ao médico, e ela explica tudo pra ele [...] minha mãe sempre tem que me explicar depois para quê eu estou tomando medicamento e para quê ele serve (S2).

De modo semelhante, uma pesquisa realizada com surdos em 2011, identificou a dependência de familiares como acompanhantes ao procurar os serviços de saúde. A mãe apareceu como a principal figura que desempenha esse papel, mas foram citados também amigo, sogra, marido e irmã (7).

A presença do familiar parece trazer algum conforto e segurança para o surdo, visto que mesmo sem ter total autonomia sobre sua saúde, confia nas informações disponíveis para os acompanhantes e seguem suas orientações.

Minha mãe me ajuda me explicando, ai eu aprendo e tomo sozinho. Não tenho medo de tomar medicamento, eu confio, minha mãe sabe. Sempre eu pergunto para ela (S4).

Qualquer adulto pode apresentar dependência de pessoas próximas, seja para acompanhamento em questões de saúde, como para apoio e compreensão acerca de outros aspectos da vida, mas no caso dos surdos, essa dependência acaba não sendo questão de escolha, mas de necessidade, devido à falta de domínio da língua oral e falta de mediador que fale LIBRAS (16).

Ao procurar atendimento sozinho apenas um dos entrevistados pareceu ser bem-sucedido. Esse dominava um pouco a linguagem oral, mas demonstrou dificuldade em expressar fielmente seus sintomas. Dois relataram não conseguir ser atendidos sozinhos e os outros nunca procuraram atendimento sem acompanhante.

Chegava lá no hospital (sozinho) e ninguém me atendia, ninguém se comunicava comigo, ai com tempo o теи problema acabou passando (S5).
Bentes et al (2011), também relataram em sua pesquisa que somente um dos doze indivíduos da sua amostra ousou ir em busca de algum serviço de saúde sem acompanhante, mas este não obteve sucesso, pois não conseguiu ser atendido pelo profissional e retornou sem o serviço que precisava (7).

A dificuldade de acesso aos serviços de Saúde, quando o familiar não pode acompanhar o surdo, também foi observada em uma pesquisa realizada em Goiânia. Os entrevistados relataram que seus familiares costumam ter muitas ocupações e afazeres e, assim, quando estão enfermos, sentem-se perdidos e solitários, por não poderem ser auxiliados por eles (4).

Embora eles expressem suas necessidades de acompanhamento, demonstram também interesse por entender o tratamento e segui-lo com autonomia quando possível. Caso houvesse a dissolução da barreira comunicativa, as informações mais acessíveis possibilitariam que os surdos se posicionassem como agentes ativos no restabelecimento da sua própria saúde.

Minha irmã me ajuda sempre. Eu dou (a receita) pra ela, ela vai comprar e me explica.

Eu memorizo, vejo as horas certinhas, vou controlando no relógio e tomo sozinho (S8).

Relatos mostram a necessidade de autonomia e o quanto gostariam de procurar atendimento sem o auxílio dos familiares, mas isso só seria possível caso os profissionais estivessem prontos a comunicar-se, ou houvesse a presença de intérpretes.

\section{Seria muito melhor se o médico soubesse LIBRAS, eu iria sozinha ao hospital (S1).}

Sobre a aquisição e administração correta de medicamentos, o grupo também não demonstrou autonomia, mas evidenciou interesse de independência caso houvesse possibilidade de comunicação.

\section{Preciso de ajuda pra me lembrar do}

medicamento. Eu sozinho não sei tomar (S9).

A presença de uma terceira pessoa para propiciar a comunicação entre o profissional e o paciente surdo pode facilitar o restabelecimento da saúde, mas também leva à falta de privacidade e autonomia do paciente (8) pois, com os intérpretes, o surdo perde a oportunidade de exposição de suas dúvidas e exposição de seus sentimentos e sintomas de forma individual e livre (5). 
Sentimentos: percepção dos surdos sobre o atendimento em saúde. Ao procurar o estabelecimento de saúde, os surdos demonstraram desejo de uma proximidade efetiva com o profissional. Mesmo sem saber se comunicar por LIBRAS, este pode atendê-los de forma humanizada, para que o paciente possa se sentir acolhido e entendido. Embora não estejam preparados para atender necessidades específicas da deficiência, devem estar aptos a prestar o seu serviço de forma humana e digna.

Meu irmão passa pro médico algumas coisas que eu estou sentindo, algumas dores, como dores de cabeça, aí meu irmão fala pra ele.

Eu calado, não falo com o médico. Mas gostaria de conversar com ele (S5).

Quando não participam do seu processo de atenção a saúde, os entrevistados demonstram sentimento de preconceito e discriminação no atendimento limitado por sua deficiência.

Depois que eu saio, as pessoas ficam falando: " $A$ h, coitadinho ele é surdo!” Eu já sei como é, percebo o jeito que ficam olhando pra mim (S8).

Os surdos que participaram do estudo de Cardoso et al (2006), também relataram sentimento de discriminação. Queixaram-se de permanecer muito tempo na fila, o que acontecia por não escutarem os seus nomes, e o profissional não o chamar de forma adequada mesmo sabendo que está lidando com um paciente surdo (4).

Ao serem questionados sobre a forma como discerniam a vez de serem atendidos nos estabelecimentos de saúde, os entrevistados deste estudo não citaram dificuldades ou preconceitos, pois sempre estavam acompanhados por familiares que os avisavam o horário e a forma de serem atendidos. Mas revelaram descontentamento, tanto por não serem informados de procedimentos aos quais seriam submetidos, quanto pela discussão sobre o seu problema de saúde, dos quais ele não poderia participar e tomar decisões.

Estava com uma forte dor no dente, fui ao dentista e ele teve que arrancar [...] Eu não fui avisado de nada, ele só foi me encaminhando e arrancou o dente. Eu fiquei com ódio do dentista por que ele me fez sentir mais dor ainda. Não gostei, por que ele não colocou anestesia (S6).
Diante de tantos obstáculos os pacientes surdos se preocupam com a situação que vivenciam, pois mesmo sendo intelectualmente capazes de cuidar da sua própria saúde, não o fazem por falta de informações e dificuldade de comunicação.

Quando o profissional trabalha valorizando o paciente, maximizando a qualidade do cuidado à saúde de forma individualizada, os benefícios da intervenção profissional são mais claros e eficazes. Houve uma nítida satisfação do entrevistado que encontrou uma enfermeira que se comunicava por LIBRAS. Dessa forma eles podem ser atendidos de maneira igualitária e participar conscientemente do seu processo de restauração da saúde.

Era uma enfermeira. Ela sabia muito bem a LIBRAS, era bonito de se ver. Fiquei muito feliz de ver essa enfermeira lá, ela me explicava dos remédios (S9).

Um etnocentrismo é percebido na área da Saúde, tanto no setor público, como no privado, quando há uma busca contínua sobre informações nessa área, especialmente para surdos (17). Esse "monopólio" das informações dificulta a inclusão dos surdos na sociedade, trazendo e eles insatisfações, preocupações, tristezas e sentimentos de exclusão.

Compreensão da terapia. Devido à deficiência, os indivíduos assim classificados estão expostos de forma mais incisiva a comorbidades, acarretando uma necessidade mais especifica do uso dos serviços de saúde, para que possa haver o estabelecimento e a manutenção da sua vida saudável (18).

Os entrevistados reconheceram a dificuldade de acesso que há nos estabelecimentos de saúde, e que eles muitas vezes não conseguem enfrentar. Eles procuram o atendimento, mas sem comunicação, não há como relacionar-se com o meio onde se pode encontrar auxílio, fazendo com que os mesmos retornem às suas residências com o problema de saúde não solucionado, como eles relatam nos trechos abaixo.

\section{Teve uma vez que eu fui ao hospital e não encontrei ninguém pra me atender lá. Tive que voltar pra casa (S9).}

As necessidades de saúde vão além de resoluções de questões orgânicas e físicas. São caracterizadas também pelo acesso a informações que nortearão a maneira do paciente lidar com seu próprio corpo. Os deficientes 
têm essas necessidades agravadas, pois além da dificuldade comum de acesso a saúde, ainda não possuem meios para obter informações de maneira adequadas a sua forma de se comunicar (5).

Há implícito nos depoimentos reflexões acerca das desigualdades de informações que são disponíveis para os ouvintes e para os surdos. O conhecimento em saúde é tão importante e fundamental para o surdo, quanto para a população em geral, portanto a restrição de meios que o atinjam, deixa-o limitado e insatisfeito.

\section{Se eles soubessem pelo menos um pouco (de}

LIBRAS), então a muitas coisas os surdos poderiam ter acesso, porque várias informações a gente sempre está sem saber. Os ouvintes têm acesso, e a gente não. Só de poucas coisas (S6).

A comunidade surda está constantemente crescendo, mas não há uma previsão legal de produção de campanhas da área da Saúde, que estejam adaptadas a LIBRAS (17). Essa adaptação precisa existir para acessar os surdos com as campanhas preventivas de doenças, de proteção imunológica com vacinas, de gravidez indesejada e outros assuntos pertinentes a saúde, e que estão disponíveis em diversas fontes para a maioria da população.

O entrevistado afirmou que, por conta da falta de acesso a informação, não foi imunizado, pois o conhecimento da campanha só o atingiu ao término da mesma, impossibilitando-o de participar ativamente desse processo de promoção de saúde.

\section{Tem algumas vacinas que eu ainda não tomei.}

Tem campanha e eu não estou sabendo, aí depois que acaba é que eu sou avisado [...] como fico sem saber acabo perdendo (S6).

Não é raro que a população surda tenha menos acesso à informação que a comunidade em geral. Por isso é necessário que haja uma comunicação mais simples e articulada, para que eles possam compreender (4). Essa falta de informação limita até mesmo o arsenal de dúvidas que os surdos possam ter, pois sem conhecimento não há o que questionar.

Ao serem questionados sobre as dúvidas relacionadas à sua saúde e/ou utilização de medicamentos, não souberam explicitar claramente os assuntos para os quais desejavam esclarecimentos. Afirmavam que as dúvidas existem, só não há pessoas capacitadas para solucioná-las.
Tem algumas coisas que eu quero perguntar, mas muitas coisas eu não consigo entender, só através da escrita (S6).

Ao serem submetidos a exames e procedimentos diagnósticos, os entrevistados relataram falta de informações acerca da metodologia que irão vivenciar, muitas vezes sendo surpreendidos por procedimentos invasivos, trazendo-lhe ainda mais medo e insegurança.

\section{Só minha irmã me explica o exame, e me diz se eu tenho que ficar parado, se tenho que tomar alguma coisa, sempre minha irmã me explica os exames (S8).}

A Secretaria de Saúde do Estado de São Paulo emitiu um documento importante para a assistência à Saúde no Estado. A Cartilha dos Direitos dos Pacientes foi elaborada pelo Conselho Estadual de Saúde, com normas que possam garantir o atendimento digno, atencioso e respeitoso para todos os acidentes. Um dos direitos é receber informações claras, objetivas e esclarecidas sobre hipóteses diagnosticas, diagnósticos realizados, exames solicitados e ações terapêuticas. As informações dessa cartilha vêm se tornando referência para outros estados, para adotar uma forma mais humanizada de lidar com os serviços de saúde (19).

Consoante a essa cartilha, é importante para o acesso do paciente aos serviços de saúde, ter informações sobre os procedimentos diagnósticos que precisa realizar e também sobre as suas condições atuais de saúde. Mas esse acesso ainda não é observado na comunidade surda. Cabe ao acompanhante explicar, mesmo que de maneira superficial, conforme seus conhecimentos básicos, o que ocorrerá com o paciente surdo. Mas nos setores ou exames nos quais não é permitido o acompanhamento, o surdo acaba ficando incomunicável, sem informação e autonomia.

Um entrevistado relatou que foi submetido a um processo cirúrgico. Nesta ocasião, aplicaram-lhe anestesia, mas o mesmo continuava sentindo muita dor e não conseguir expor esse problema para o médico. Como não havia ninguém da sua família por perto, teve que suportar as dores, sem se comunicar. Expressou-se com muita tristeza e indignação sobre esse episódio.

Eu fiquei muito triste com essa situação que aconteceu comigo. Eu tenho direito como qualquer outra pessoa, de ficar boa. O jeito que o médico agiu comigo foi muito errado (S9). 




Em uma análise das prescrições emitidas em um hospital de Fortaleza, $73 \%$ dos itens contidos nelas foram considerados ilegíveis. Também foram encontradas outras irregularidades quanto a ausência da forma farmacêutica, as dosagens e horário (20).

Quanto à prescrição, todos os entrevistados afirmaram não a entender completamente. Ao serem questionados sobre os horários, as dosagens (como $\mathrm{mL}$, gotas) e as concentrações, demonstraram falta de conhecimento, dúvidas e interesse em aprender e perguntar para os ouvintes o significado desses termos. Alguns conseguem entender e seguir seu tratamento, outros ainda são muito dependentes.

Não entendo nada da receita, o médico me explica falando o que é. Depois que ele me explica eu entendo um pouco. Não entendo gotas, pergunto: "Que remédio é esse? O que é isso? Gotas?" Ai a pessoa me explica (S4).

Além da utilização de termos técnicos, desconhecidos aos surdos, que estão presentes na prescrição, eles reclamam da caligrafia. Como o português é sua segunda língua (11), quando as palavras não estão bem claras, fica ainda mais difícil o processo de captação da informação.

A ilegibilidade das prescrições também é causa de queixas entre a população em geral. Em seu trabalho sobre avaliação das prescrições médicas, Aguiar et al (2006) afirmaram que: "Não importa quão precisa ou completa seja uma prescrição, se ela não puder ser lida." (20) A legibilidade condiciona a comunicação e pode ocasionar interrupção ou alteração na assistência ao paciente, trazendo danos ao mesmo. Assim, é fundamental tanto para os surdos quanto para os ouvintes, que estes possam compreender as informações expostas nas prescrições, para a segurança do seu tratamento.

O papel do farmacêutico é de um serviço complementar ao serviço médico, visto que o paciente sai do consultório com uma prescrição, mas essa só será de fato útil, se forem avaliados também os fatores que podem interferir no tratamento do paciente como hábitos alimentares, tabagismo, histórico de reações alérgicas, uso de outros medicamentos ou drogas, outras doenças ou até mesmo a falta de adesão. Com a atenção farmacêutica há possibilidade de intervenção nesses fatores, para um melhor resultado terapêutico (21). Dessa forma, o farmacêutico, quando acessível, pode auxiliar o surdo em seu tratamento, fornecendo a ele conhecimentos sobre sua saúde e consequentemente mais autonomia para lidar com ela.
Sobre o acesso à farmácia e o relacionamento com o farmacêutico, foi observado que há uma grande lacuna entre o paciente surdo e o medicamento, visto que além de não o compreender, não têm acesso ao profissional capacitado para instruí-lo. Os entrevistados afirmaram que nunca conversaram com um farmacêutico e nem foram sozinhos à farmácia.

\section{Nunca conversei com um farmacêutico (S1). \\ Nunca fui à farmácia. Quando sinto dor de cabeça minha mãe me dá remédio, não sei tomar sozinho (S3).}

O farmacêutico é o profissional da área da Saúde que presta assistência, com seus conhecimentos da área, tanto em farmácia, quanto em laboratórios e indústria. Somente a formação cientifica não é suficiente para cumprir excelentemente a sua função. Ele precisa desenvolver também seu papel social, promovendo educação em saúde e instruções sobre o uso racional de medicamentos, e isso se dá através da comunicação (22). Para tanto, também é importante mostrar habilidade de comunicação através da linguagem dos sinais.

\section{CONCLUSÃO}

Esse estudo permitiu observar o acesso aos serviços de Saúde, do ponto de vista do surdo, e constatar que estes enfrentam muitas dificuldades e encontram obstáculos no seu atendimento. Isto pode ser visto na evidente escassez de informações que têm sobre os serviços de saúde, de exames, procedimentos e tratamentos a que são submetidos, bem como de campanhas de educação em saúde e de proteção imunológica.

Em busca de contornar as dificuldades, são utilizadas formas alternativas de comunicação, como a escrita, mímicas e a presença de um acompanhante, na maioria das vezes um membro da família, visto que nos estabelecimentos não se encontram profissionais que se comuniquem por LIBRAS e nem intérpretes, embora os próprios surdos saibam que esse é um direito que lhes assiste a própria Constituição Brasileira.

Os entrevistados demonstraram sentimentos negativos quanto à forma de serem atendidos, por vezes sentindo-se discriminados, isolados e desrespeitados. Mesmo assim mostraram interesse em aprender e compreender o mundo à sua volta, ao questionarem seus familiares sobre sua Saúde e buscarem autonomia no seu tratamento. 


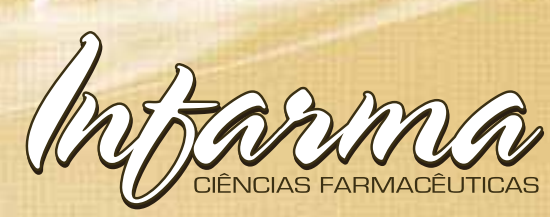

A realidade de acesso à Saúde conforme os princípios de universalidade, igualdade e integralidade estabelecidos na criação do SUS (23), ainda não pode ser contemplada na comunidade surda, pois ainda há muitas barreiras que tornam os profissionais da Saúde inacessíveis, principalmente por falta de capacitação deste. Além disso, a própria sociedade ainda vê o surdo com alguém incapaz de tomar suas próprias decisões em rela-

\section{REFERÊNCIAS}

1. BRASIL. Decreto $\mathrm{n}^{\circ} 5.296$ de 2 de dezembro de 2004. Estabelece normas gerais e critérios básicos para a promoção da acessibilidade das pessoas portadoras de deficiência ou com mobilidade reduzida, e dá outras providências. Diário Oficial da União 1990; 2 dez.

2. IBGE. Instituto Brasileiro de Geografia Estatistica. Censo demográfico brasileiro 2010. Brasília: IBGE; 2010.

3. BRASIL. Decreto $\mathbf{n}^{\mathbf{0}} \mathbf{5 . 6 2 6}$, de 22 de dezembro de 2005. Regulamenta a Lei ${ }^{\circ} 10.436$, de 24 de abril de 2002, que dispõe sobre a Língua Brasileira de Sinais - Libras, e o art. 18 da Lei no 10.098 , de 19 de dezembro de 2000. Diário Oficial da União 2005; 22 dez.

4. Cardoso AHA, Rodrigues KG, Bachion MM. Percepção da pessoa com surdez severa e/ou profunda acerca do processo de comunicação durante seu atendimento em saúde. Rev Latino-am Enferm 2006; 14(4):553-560. DOI 10.1590/S0104-11692006000400013.

5. Santos EM, Shiratori K. A necessidade de saúde no mundo so silêncio: um diálogo com os surdos. Rev. Eletr Enferm. 2004; 6(1). DOI 10.1590/S0080-62342005000400007

6. Cesate JC, Corrêa AK. Humanização do atendimento em saúde: conhecimento veiculado na literatura brasileira de enfermagem. Rev Latino-am Enferm 2005; 13(1):105111. DOI 10.1590/S0104-11692005000100017

7. Bentes IMS, Vidal ECF, Maia RE. Percepção da pessoa surda acerca da assistência a saúde em um municipio de médio porte: estudo descritivo-exploratório. Rev. Bras Enferm On Line. 2011; 10(1): DOI 10.17665/1676-4285.

8. Costa LSM, Almeida RCN, Mayworn MC, Alves PTF, Bulhões PAM, Pinheiro VM. O atendimento em saúde atraves do olhar da pessoa surda: avaliação e propostas. Rev Bras Clin Med 2009; 7:166-170.

9. Souza ECF, Vilar RLA, Rocha NSPD, Uchoa AC, Rocha PM. Acesso e acolhimento na atenção básica: uma análise da percepção dos usuários e profissionais de saúde. Cad. Saúde Pública. 2008; 24 (Sup 1):100-110. DOI 10.1590/S0102-311X2008001300015

10. Castro SS, Levefèvre F, Levefèvre AMC, Cesar CLG. Acessibilidade aos serviços de saúde por pessoas com deficiência. Rev Saúde Pública 2011; 45(1): 99-105. DOI 10.1590/S0034-89102010005000048

11. Chaveiro N, Barbosa MA. Assistência ao surdo na área da saúde como fator de inclusão social. Rev Esc En- ção à sua saúde e terapia, mantendo-lhes na dependência de outras pessoas. Sendo assim, o primeiro passo para inclusão, humanização e a acessibilidade aos serviços de Saúde para as pessoas surdas só poderá ser efetivada quando mais profissionais de saúde compreenderem a importância de se comunicarem por LIBRAS ou o direito teórico de ter intérpretes nos estabelecimentos de saúde seja colocado em prática.

ferm USP 2005; 39(4):417-22. DOI 10.1590/S008062342005000400007.

12. BRASIL. Constituição (1988). Constituição da República Federativa do Brasil. 33 ed. São Paulo: Saraiva, 2004b.

13. Machado WCA, Machado DA, Figueiredo NMA, Tonini T, Miranda RS, Oliveira GMB. La lengua de signos: Cómo interactúa el personal de enfermería para atender a los clientes sordos? J. Res. Fundam. Care. 2013; 5(3):283-292. DOI 10.9789/2175-5361

14. Veet V. Mídia e deficiência (Série diversidade). Brasília: fundação Banco do Brasil; 2003.

15. Aragão JS, Magalhães IMO, Coura AS, Silva AFR, Cruz GKPC, França ISX. Acess and comunication of deaf adults: a voice silenced in health services. J. Res. Fundam. Care. 2013; 6(1):1-7. DOI 10.9789/2175-5361

16. Marin CR, Góes MCR. A experiência de pessoas surdas em esferas de atividade do cotidiano. Cader. Cedes 2006; 26(69) DOI 10.1590/S0101-32622006000200007

17. Novaes EC. Surdos - Educação, Direito e Cidadania. São Paulo: WAK Editora, 2010.

18. França IXS, Pagliuca LMF. Acessibilidade das pessoas com deficiência ao SUS: fragmentos históricos e desafios atuais. Rev. RENE. 2008; 9(2):129-137. DOI 10.1590/ S1413-81232012000700022

19. SP. São Paulo. Cartilha dos direitos do paciente. São Paulo, 1995.

20. Aguiar G, Alves LS, Magalhães MAF. Ilegibilidade e ausência de informação nas prescrições médicas: fatores de risco relacionados a erros de medicação. Rev. Bras. Prom. Saúde. 2006; 19(2)

21. Vieira FS. Possibilidades de contribuição do farmacêutico para a promoção da saúde. Rev Ciênc. Saúde Colet 2005; 12(1):213-220. DOI 10.1590/S141381232007000100024

22. Oliveira MJL. Assistência Farmacêutica: a percepção dos gestores e profissionais de saúde em São Luís (MA). Porto Alegre, 2004. Dissertação (Mestrado em Ciências Farmacêuticas) - UFRGS, 2004.

23. BRASIL. Lei $n^{\circ} 8.080$, de 19 de setembro de 1990. Dispõe sobre as condições para a promoção, proteção e recuperação da saúde, a organização e o funcionamento dos serviços correspondentes e dá outras providências. Diário Oficial da União 1990; 19 set. 